\title{
Herpes Radiculitis Following Surgery for Symptomatic Cervical Foraminal Stenosis
}

\author{
Juergen Grauvogel, Vassilios I. Vougioukas
}

Can. J. Neurol. Sci. 2008; 35:661-663

A 56-year-old man was referred to our hospital with complaints of slowly progressive dysesthetic pain in the distribution of the right C-8 nerve root. Symptomatology started approximately eight weeks prior to admission after a two week stay in Africa. Examination on admission revealed motor weakness of the hand intrinsics and abductor pollicis brevis muscle on the right side. Froment's sign was positive and hypesthesia of the fingers 4 and 5 of the right hand was noticed. Deep tendon reflexes were equal and active bilaterally. Neck motion was not limited in any way. The patient did not have any signs of cervical myelopathy.

Electromyography which was performed four weeks prior to admission showed pathologic spontaneous activity and signs of axonal degeneration for the right $\mathrm{C}-8$, and to a lesser extent for the right $\mathrm{C}-7$ nerve root.

Cervical magnetic resonance (MR) and computed tomogram (CT) images demonstrated spondylosis and osseous narrowing of the right $\mathrm{C} 7 / \mathrm{Th} 1$ foramen with compression of the right $\mathrm{C}-8$ nerve root. A CT-guided diagnostic block anesthesia of the right C-8 nerve root with bupivacaine led to temporary total pain relief.

Based on clinical findings and diagnostic workup we decided to perform a minimally invasive posterior foraminotomy. Initial postoperative course was uneventful. Significant reduction of preoperative symptoms corresponding to the right $\mathrm{C} 8$ nerve root was noted.

On the second postoperative day the patient developed new motor deficits on his right arm corresponding to a C-6 and C-7 lesion. Urgently conducted cervical MR imaging failed to show new pathological findings. An extensive blood and CSF workup was initiated in order to rule out bacterial or viral infection. Blood serum and cerebroprinal fluid (CSF) were tested for borreliosis, treponema pallidum, immunglobulines ( $\mathrm{IgG}, \operatorname{IgM}$, $\operatorname{IgA}, \mathrm{IgE}$ ), Varicella zoster virus (VZV), Herpes simplex virus (HSV) and Human immunodeficiency virus (HIV). The CSF examination revealed 28 leukocytes $/ \mathrm{mm}^{3}$ and an increased protein content of $1920 \mathrm{mg} / \mathrm{l}$. Elevated specific CSF/serum antibody indices for HSV and VZV (3.60 and 2.69 respectively) were verified, indicating an intrathecally production of virusspecific antibodies. Diagnosis of herpes virus-radiculitis was confirmed and intravenous treatment with aciclovir started. Neurological deficits did not, however, resolve during hospital stay but improved considerably after a three month period.

\section{Discussion}

Varicella zoster virus is an alphaherpesvirus causing two distinct syndromes. The primary infection (Chicken pox) usually

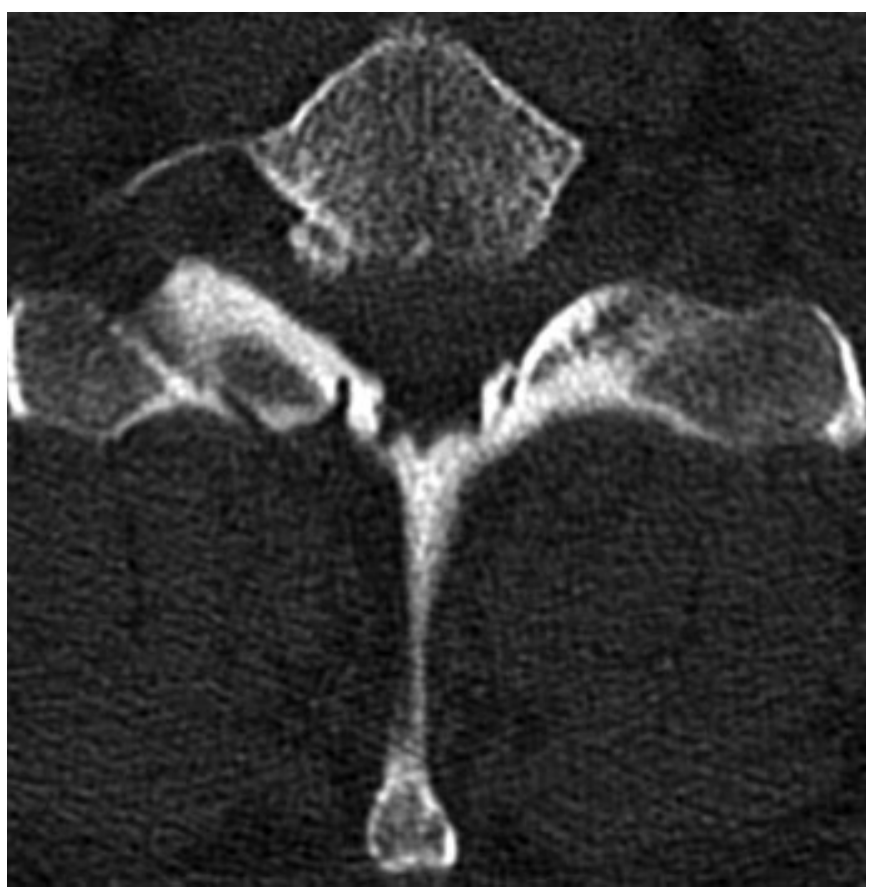

Figure 1. Axial CT scan (bone window) of the cervical spine at the level C7/Th1 showing foraminal stenosis on the right side.

presents clinically as a highly contagious rash, consisting of clusters of vesicles on the skin and mucous membranes. ${ }^{1}$ The symptoms usually resolve within a few weeks. However the virus establishes latency in sensory ganglia and may reactivate to cause herpes zoster or shingles. ${ }^{2}$ The exact mechanism of reactivation is still unknown. Under the condition of declined virus-specific cell-mediated immune responses reactivation of VZV leads to extensive cell to cell spread of the virus within the

\footnotetext{
From the Department of Neurosurgery, Albert Ludwigs University, Freiburg, Germany. Received March 10, 2008. Final Revisions Submitted May 13, 2008.

Correspondence to: Juergen Grauvogel, Department of Neurosurgery, Albert Ludwigs
} University of Freiburg, Breisacherstr. 64, 79106 Freiburg, Germany. 


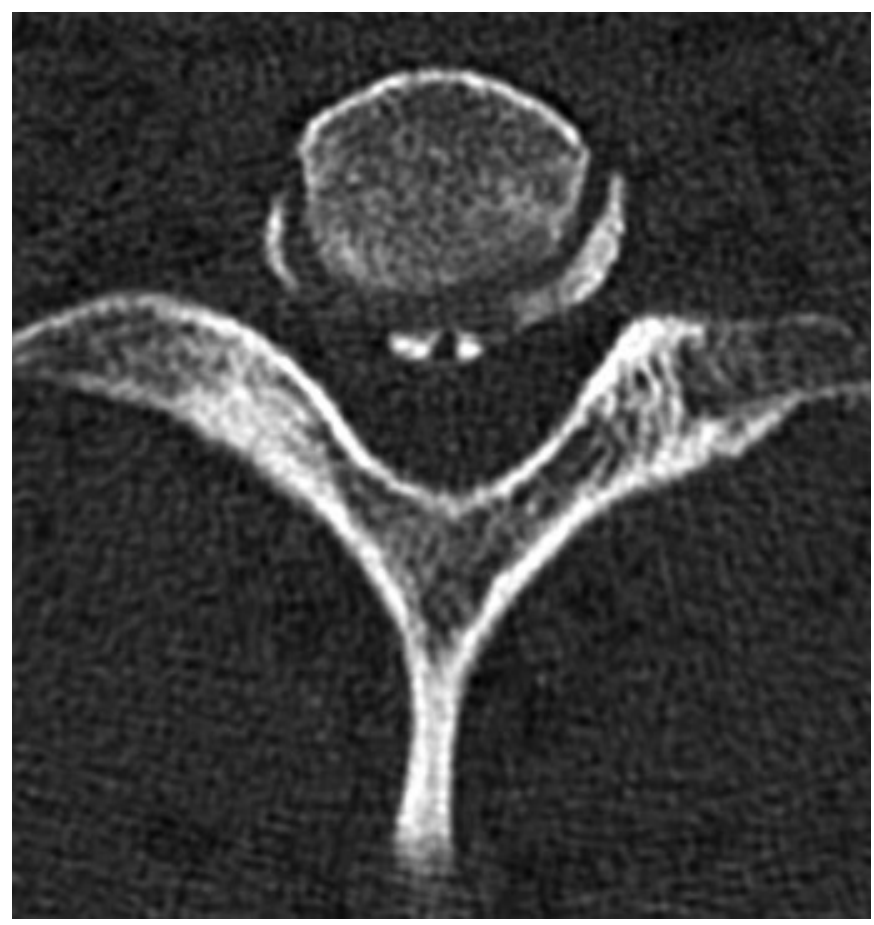

Figure 2. Axial CT scan (bone window) of the cervical spine at the level C6/C7.

ganglia, an intense local inflammatory response and widespread necrosis of glial cells and neurons. ${ }^{3}$ Varicella zoster virus spreads centrifugally down the sensory nerve and is then released from sensory nerve endings in the skin, causing the typical dermatomal rash of herpes zoster. During acute Herpes zoster, T cells may also become infected at the site of local cutaneous replication. If the host response is impaired, $\mathrm{T}$ cells can transport the virus to lungs, liver, brain, and other organs. ${ }^{3}$ Therefore, reactivation of the virus occurs primarily in older individuals, aged 60-70 years ${ }^{4}$ or in patients with immunosuppressive diseases or in an immunosuppressive state. ${ }^{5}$ Reactivation of the virus after surgery was also previously described in literature. ${ }^{6,7}$ The annual incidence of Herpes zoster is about 1.5 to 3.5 cases $11000^{8}$ and the lifetime risk is estimated to be 10 to $20 \% .^{9}$

The symptoms of Herpes zoster or shingles are tingling, itching and pain in the involved nerve distribution as well as, in the majority of cases, an erythematous maculopapular rash. Weakness of the involved muscles may also be present. ${ }^{4}$ However there are cases without rash, the so called Herpes zoster sine herpete. ${ }^{10}$ Zoster sine herpete is currently defined as dermatomal-distribution pain without antecedent rash. Before polymeras chain reaction (PCR), verification was limited to serologic testing. In 1970 Easton described the first case with acute pain of trigeminal distribution without rash, which was associated with a quadrupling of antibody to varicella zoster virus, but not antibody to herpes simplex virus. ${ }^{11}$ Gilden et al reported two patients with prolonged radicular pain of thoracic distribution without rash. The diagnosis was confirmed via PCR analysis. Amplifiable varicella zoster viral DNA, but not herpes simplex virus DNA, was found in cerebrospinal fluid and mononuclear blood cells. ${ }^{12}$

Athwal et al reported a case of herpes zoster in the ulnar nerve distribution. This 36-year old patient presented with ulnar wrist pain, paraesthesia in the ulnar nerve distribution and emerging motor weakness of the right hand associated with clusters of erythematous vesicles in the ulnar nerve distribution. ${ }^{1}$

Herpes zoster can affect any dermatomal distribution, although it is most common on the trunk. ${ }^{1}$ Whereas there are a lot of reports in the literature of Herpes zoster affecting the trunk and the cranial nerves, there are only a few reports of Herpes zoster affecting the upper extremity. ${ }^{1,5}$ In these cases diagnosis is usually made by positive PCR findings or detection of intrathecal antibody synthesis (CSF/serum antibody index $\geq$ 2.0). ${ }^{13}$ Whereas PCR of HSV DNA is a sensitive and specific test for instance in the diagnosis of HSV encephalitis, PCR for VZV DNA does not always provide this sensitivity. The reason for this may be the usually more protracted and chronic clinical course of VZV-mediated disease. ${ }^{14}$ Moreover results of PCR diagnostics seem to be time-dependent. The percentage of PCR-positive cases is reported to drop sharply after one-to-two weeks. Furthermore some cases are reported in the literature revealing either negative PCR results for VZV DNA particularly in the early course of the disease or detection of VZV DNA only in

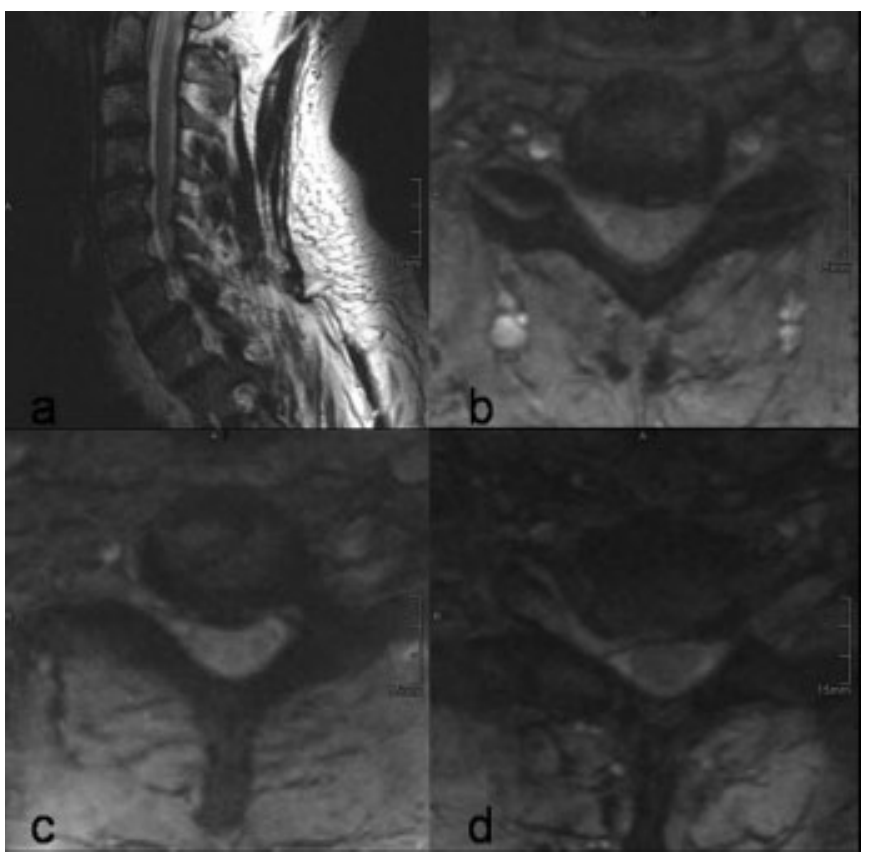

Figure 3. T2-weighted MRI of the cervical spine: a) sagittal view, $b$ ) axial view at the level C5/C6, c) axial view at the level C6/C7, d) axial view at the level C7/Th1. 
severe cases of VZV encephalitis. ${ }^{13,14}$ The complimentary CSF testing for virus-specific antibodies together with PCR is therefore recommended. ${ }^{13}$

Aciclovir, valaciclovir, famciclovir and bruvidin are the four antiviral drugs approved for use in Europe for the treatment of herpes zoster, whereas in the United States only three drugs are in use (acyclovir, valacyclovir and famciclovir). ${ }^{15}$ These drugs inhibit the replication of the Varicella zoster virus, resulting in decreased viral shedding, accelerated healing of lesions and decreased duration and severity of acute pain. ${ }^{16}$ Antiviral treatment should be initiated in patients with post-herpetic neuralgia risk factors (older age, greater degree of involved skinsurface area and more severe pain at presentation), immunosuppression and zoster ophtalamus to prevent serious complications. ${ }^{8,16}$ Ideally antiviral therapy should be initiated within 72 hours of rash onset. ${ }^{2}$ However some patients will still benefit from delayed treatment. ${ }^{17}$

In the presented case the typical maculopapular rash was completely absent. Clinical symptoms in combination with the EMG findings showing signs of axonal degeneration of the right $\mathrm{C} 8$ nerve root and the cervical images (Figure 1) led, in our case, to the diagnosis of a symptomatic foraminal stenosis at the level C7/Th1. The postoperative course with development of additional neurological deficits forced us to conduct blood serum and CSF studies that finally revealed the additional diagnosis of herpes radiculitis.

Therefore the patient presented here probably harboured two different entities: C-8 nerve root compression syndrome caused by foraminal stenosis at $\mathrm{C} 7 / \mathrm{Th} 1$ and, at time of surgery, asymptomatic HSV-neuritis. The electrophysiological signs of C-7 nerve root involvement pointed to activation of HSV in the C-7 nerve root distribution postoperatively. Lumbar puncture and evaluation of CSF finally led to the diagnosis of this second entity. Clinical manifestation of HSV-neuritis secondary to surgery was probably caused either by the immunosuppressive effect of anaesthesia or surgery itself as described previously in the literature. ${ }^{6,7}$

Although herpes radiculitis in the upper extremity is a rare condition, the diagnosis of HSV- or VZV-neuritis should be kept in mind and should be included in the differential diagnosis of segmental pain and weakness in the extremities, if results of electrophysiological testing do not strongly correspond with imaging findings.

\section{REFERENCES}

1. Athwal GS, Bartsich SA, Weiland AJ. Herpes zoster in the ulnar nerve distribution. J Hand Surg [Br]. 2005;30(4):355-7.

2. Gilden DH, Kleinschmidt-DeMasters BK, LaGuardia JJ, Mahalingam R, Cohrs RJ. Neurologic complications of the reactivation of varicella-zoster virus. N Engl J Med. 2000; 342(9):635-45

3. Abendroth A, Arvin AM. Immune evasion as a pathogenic mechanism of varicella zoster virus. Semin Immunol. 2001; $13(1): 27-39$

4. Merchut MP, Gruener G. Segmental zoster paresis of limbs. Electromyogr Clin Neurophysiol. 1996;36(6):369-75.

5. Matondo P, Lungu G, Njobvu P. Claw hand as a complication of herpes zoster. Trop Doct. 2000;30(1):33-5.

6. Godfrey EK, Brown C, Stambough JL. Herpes zoster--varicella complicating anterior thoracic surgery: 2 case reports. J Spinal Disord Tech. 2006;19(4):299-301.

7. Haverkos HW, Pazin GJ, Ho M, Nelson PB. Reactivation of type 2 herpes simplex virus by thoracolumbar neurosurgery. Ann Intern Med. 1984;101(4):503-4.

8. Donahue JG, Choo PW, Manson JE, Platt R. The incidence of herpes zoster. Arch Intern Med. 1995;155(15):1605-9.

9. Ragozzino MW, Melton LJ, 3rd, Kurland LT, Chu CP, Perry HO. Population-based study of herpes zoster and its sequelae. Medicine (Baltimore). 1982;61(5):310-6.

10. Kleinschmidt-DeMasters BK, Gilden DH. Varicella-Zoster virus infections of the nervous system: clinical and pathologic correlates. Arch Pathol Lab Med. 2001;125(6):770-80.

11. Easton HG. Zoster sine herpete causing acute trigeminal neuralgia. Lancet. 1970;2(7682):1065-6.

12. Gilden DH, Wright RR, Schneck SA, Gwaltney JM, Jr., Mahalingam R. Zoster sine herpete, a clinical variant. Ann Neurol. 1994;35(5):530-3.

13. Schultze D, Weder B, Cassinotti P, Vitek L, Krausse K, Fierz W. Diagnostic significance of intrathecally produced herpes simplex and varizella-zoster virus-specific antibodies in central nervous system infections. Swiss Med Wkly. 2004;134(47-48):700-4.

14. Gilden DH, Bennett JL, Kleinschmidt-DeMasters BK, Song DD, Yee AS, Steiner I. The value of cerebrospinal fluid antiviral antibody in the diagnosis of neurologic disease produced by varicella zoster virus. J Neurol Sci. 1998;159(2):140-4.

15. Gross G, Schofer H, Wassilew S, Friese K, Timm A, Guthoff R, et al. Herpes zoster guideline of the German Dermatology Society (DDG). J Clin Virol. 2003;26(3):277-89; discussion 291-3.

16. Gnann JW, Jr., Whitley RJ. Clinical practice. Herpes zoster. N Engl J Med. 2002;347(5):340-6.

17. Wood MJ, Shukla S, Fiddian AP, Crooks RJ. Treatment of acute herpes zoster: effect of early $(<48 \mathrm{~h})$ versus late $(48-72 \mathrm{~h})$ therapy with acyclovir and valaciclovir on prolonged pain. J Infect Dis. 1998;178 Suppl 1:S81-4. 